\title{
NOTAS SOBRE LA COLONIZACIÓN AGRÍCOLA EN EL PROTECTORADO DE ESPAÑA EN MARRUECOS
}

\author{
Vicente GOZÁLVEZ PÉREZ \\ Universidad de Alicante
}

Las estadísticas españolas sobre el Protectorado en el norte de Marruecos se inauguran en 1941 con la publicación del primer Anuario Estadístico ${ }^{1}$; en éste y sucesivos se ofrecen numerosos datos sobre la agricultura, tanto en superficies cultivadas como en producciones, aunque se subraya su carácter de estimaciones, generalmente con infravaloración. En cualquier caso interesa destacar dos hechos; en aquellos años, el suelo cultivado es muy escaso, aunque en aumento: para 1941 el Anuario estina que ocupa el 7'5\% (154.000 ha.) de la superficie total del Protectorado; el carácter montañoso de la región sería la principal causa, y por ello tal proporción se reduce al 3'8\% en la zona central de Gomara, mientras supera el $13 \%$ en la Región occidental, la más llana y con pluviometría favorable. El Anuario de 1955, el último que se publica, da una superficie cultivada de 372.000 hectáreas, que representarían cerca del $20 \%$ del total; tal aumento de suelo cultivado es en parte real y en parte producto de la subestimación inicial. El segundo hecho a destacar es el déficit de la producción agrícola para el autoabastecimiento, incluso en las producciones más elementales, los cereales, que a su vez ocupan en torno al $90 \%$ del suelo cultivado ${ }^{2}$.

1 Ministerio de Trabajo. Dirección General de Estadística, Zona de Protectorado y de los territorios de soberanta de España en el norte de África. Anuario Estadistico 1941, Madrid, 1942, 319 pp.

2 En concreto, el Anuario de $1941(\mathrm{p} .45)$ estima los siguientes déficits: 
La insuficiencia de la producción agrícola viene determinada tanto por condicionantes naturales como humanos, es decir, por un lado superficie de cultivo escasa e insuficiencia pluviométrica, sobre todo en el extremo oriental del Protectorado; por otro, el atraso en las técnicas, tanto en maquinaria (predominio del arado romano de madera entre los marroquíes), como la falta de abonado, de regadío, o de selección de semillas, entre otros ${ }^{3}$, además de un acusado minifundismo entre los

47.000 Qm de cebada, sobre una producción local de $500.000 \mathrm{Qm}$; la cosecha de trigo $(200.000 \mathrm{Qm})$ representa el $25 \%$ del consumo; en maíz el déficit se eleva al $41 \%$ de la cosecha $(29.000 \mathrm{Qm})$, y en leguminosas al $23 \%$, sobre una cosecha de 63.000 Qm.

Tomás García Figueras, excelente conocedor del Marruecos bajo administración española, al que dedicó una abundantísima bibliografía, escribía en 1947, «...la Zona es grandemente deficitaria en artículos básicos para la alimentación, como el trigo, el aceite, el azúcar y las legumbres, para comprender el intéres que hay en mejorar su producción", publicado en Diario de África, agosto y septiembre 1947, y reeditado en «La evolución agricola de la Zona", Miscelánea de estudios varios sobre Marruecos, Tetuán, Editora Marroquí, 1953, pp. 205 221.

${ }^{3}$ Así, en los primeros Anuarios estadísticos se encuentran textos como los que siguen: "La maquinaria importada presenta cifras muy reducidas que demuestran que hasta ahora sólo las grandes explotaciones oficiales o las grandes explotaciones llevadas por propietarios no indígenas, utilizan medios mecánicos para los cultivos" (Anuario de 1942, p. 48).

«Durante el año se han transformado en regadío 235 ha., que unidas a las de años anteriores, dan un total de 2.549 transformadas, continuando en curso los trabajos sobre otras 1.058* (Anuario de 1943, p. 46).

«En los Centros oficiales de enseñanza agrícola sólo han cursado estudios 33 alumnos indígenas, sin que se haya expedido certificado alguno de aptitud" (Anuario de 1943, p. 46).

«En las fincas de Telata de Raisana y sobre una superficie de 259 ha. se ha realizado un asentamiento de 12 colonos españoles... Con esta colonia agrícola... se persigue como principal finalidad hacer ver al indígena las ventajas que para su economía representa el abandono de sus prácticas de cultivo e ir aceptando, por su sistema gradual, los modernos procedimientos» (Anuario de 1944, p.37).

«... [entre los agricultores marroquíes] hay predominio de pequeños predios, con superficies inferiores a 3 hectáreas... (Anuario de 1945, p. 37); en tal superficie se contabilizan el 78\% de las 107.520 explotaciones censadas» (Anuario de 1946, p. 39).

«Exponente de importancia en el desarrollo de una economía agrícola es el uso del abono, pero parece ser que el indígena no muestra todavía apetencia por 
agricultores marroquíes. Si a las insuficiencias que presenta la agricultu$\mathrm{ra}$, añadimos la inexistencia de economía industrial y las mayores dificultades humanas para su desarrollo, quedan bien justificados los esfuerzos iniciales para mejorar la agricultura local. Sin duda, la ampliación del regadío es uno de los índices expresivos de tal intención: según las cifras publicadas en los primeros Anuarios estadísticos, el regadío (huerta en el Anuario) ocuparía 3.832 ha. en 1936, 5.497 en 1941 y 7.718 en 1946.

En el contexto indicado, las páginas que siguen ofrecen algunos apuntes sobre las características de la colonización agrícola realizada por los españoles en sus primeros años de actuación, después de la ocupación efectiva del territorio, finalizada en 1927. En estos años la colonización agrícola es incentivada por estos motivos, entre otros: justificar la existencia del protectorado con actuaciones que, como ésta, debían tener repercusiones patentes con el desarrollo de aquella región; subsanar las graves carestras alimenticias existentes y que se agravan con motivo de la guerra civil española.

\section{Principales actuaciones de la Administración española para mejorar la agricultura del Protectorado}

La dominación militar española sobre el territorio del Protectorado permitió el establecimiento de colonos españoles, que aumentaron notablemente en los años 1916-19, procedentes tanto del sur y levante peninsular, como del Oranesado, al mismo tiempo que surgen diversos organismos y sociedades de apoyo a la colonización. Las regiones oriental o de Quert, en las cercanfas de Melilla, y de Yebala, donde se encuentra Tetuán, capital del Protectorado, fueron las primeras elegidas por los colonos españoles, por obvias razones de seguridad, además de contar estas regiones con ciertas posiblidades de regadio a partir de los ríos Muluya y Martín, respectivamente. Este primer intento de colonización se malogró momentáneamente con la sublevación marroquí

estos regeneradores de la tierra, limitándose al uso del abono animal» (Anuario de 1946, p. 40). 
de $1921^{4}$; asi, p.e., se consigna expresamente para los poblados de Monte Arruit, Zeluán o Batel ${ }^{5}$ (situados en el entorno de Melilla-río Muluya, y que, como otros del Protectorado, tuvieron su origen en campamentos militares establecidos durante la ocupación española ${ }^{6}$, que en los años anteriores a 1921 alcanzaron un notable crecimiento con colonos españoles, en buena parte procedentes de Argelia, atraf́dos por el primer impulso dado por la Compañía Española de Colonización (préstamos en dinero, semillas o aperos) ${ }^{7}$.

La total conquista y pacificación del Protectorado en 1927, serf́a el necesario punto de partida para el normal desarrollo de la colonización agrícola. Así, se desarrollan nuevas compañías de colonización, como la Agrícola del Lucus, una de las más importantes, al mismo tiempo que se establecen algunos particulares provistos de notable capital ${ }^{8}$. Entre las actuaciones de la Administración española tendentes a la mejora de la agricultura, ya en 1913 se creó el Servicio de Agricultura dentro de la Delegación de Fomento de los Intereses Materiales', cuya acción territorial se iría extendiendo con la pacificación. Sin embargo sería a

${ }^{4}$ Ruiz Albéniz, Víctor, Monografia sobre colonización rural en Marruecos español, Madrid, Imprenta Sáez Hermanos, 1930, 261 pp. Cfr. pp. 21-23.

${ }^{5}$ Ruiz Albéniz, V., Ob. cit., p. 116,133.

${ }^{6}$ Delegación de Asuntos Indígenas. Servicio de Intervenciones, Anuario, Tetuán, 1955, 505 pp. (mecanografiado, ejemplar depositado en la Biblioteca Nacional, Madrid).

${ }^{7}$ La Compañia Española de Colonización fue fundada en 1915, con domicilio social en Madrid y retuán, y capital nominal de 1'5 millones de pesetas, según Morales Lezcano, V., España y el norte de Áfica: El Protectorado en Marruecos (1912-56), Madrid, U.N.E.D., 1984, 249 pp. Cfr. p. 188. Según datos aportados por este autor, también se constituyen en estos años otras sociedades dedicadas de modo exclusivo o preferente a la colonización agrícola, como la "Sociedad Hispano-Africana de Crédito y Fomento", Madrid, 1911; "Oliva-Ensanche de Tetuán, S.A.", Tetuán, 1913; "África Industrial, S.A.", Tetuán, 1917; "Agrícola del Lucus, S.A.", Larache, 1921; "Compañía Nacional de Colonización Africana, ALENA", Barcelona, 1929.

${ }^{8}$ Ruiz Albéniz, V., Ob. cit., p. 133-34.

9 García Figueras, T., «La acción económica de España en Marruecos», Información Comercial Española, 1950, y reeditado en Miscelánea de Estudios varios sobre Marruecos, Tetuán, 1953, pp. 224-233. 
partir de 1927, año en que se completa la pacificación del Protectorado, cuando se emprenden acciones más decididas en la colonización y mejoras agrarias. Asi, en enero de 1927, se cré́ la Dirección de Colonización, que desde el principio fomentó las enseñanzas prácticas de agricultura en las Granjas de Melilla (para alumnos españoles) y de Larache (para alumnos marroquíes) ${ }^{10}$, que a su vez se complementaban con las Oficinas de Propaganda Agrícola (especie de granjas comarcales) ${ }^{13}$. El Gobierno de la República española suprimió la Dirección de Colonización, traspasando sus competencias a las Delegaciones primitivas, mientras, después de los avatares de la guerra civil, en 1941 se creaba la Delegación de Economía, Industria y Comercio, que, entre otros, contaba con Servicios Técnicos de Agricultura, Ganadería y Montes.

También hay que destacar, entre las instituciones de fomento a la agricultura la implantación de los Créditos o Pósitos Agrícolas en 1926, así como de los Sindicatos Agrícolas a partir de 1928, que buscaron tener verdadero carácter de cooperativas de producción ${ }^{12}$, es decir, segín señala en 1929 el director de la Dirección de Colonización, los sindicatos deberían hacer en común la venta de las cosechas y la compra de los productos requeridos por los agricultores, evitando los intermediarios; también deberían obtener prestamos colectivos. En las cabilas los sindicatos deberían mejorar el regadío, realizar bonificaciones de terrenos pantanosos e introducir maquinaria agrícola moderna ${ }^{13}$.

${ }^{10}$ Las enseñanzas agrícolas impartidas en estas escuelas eran eminentemente prácticas y estaban atendidas por ingenieros y peritos agrónomos, así como por ayudantes, además de un profesor de lengua. Disponían de un edificio para la docencia y sendas residencias para alumnos solteros y casados, aunque en Larache los segundos vivían en pequeñas viviendas. Las prácticas se realizaban en viveros y campos de experimentación y demostración de la Granja (Archivo General de la Administración, Caja AF-M-1642).

${ }^{11}$ Ruiz Albéniz, V., Ob. cit. p. 218, 226-27.

12 Ruiz Albéniz, V. Ob. Cit., pp. 168-179.

13 Archivo General de la Administración (AGA), Caja AF-M-1642. Oficio fechado en Tetuán el 5-12-1929 por Angel de Torrejón, Director de la Dirección de Colonización. 
Los viveros forestales y agrícolas fueron instrumento notable para la mejora agrícola del Protectorado, aunque en 1929 se señala que «los resultados son inferiores al esfuerzo realizado» ${ }^{14}$, debido, sobre todo, a las malas condiciones en que se haćan el trasporte y plantación del árbol, así como por la falta de cuidados. Los viveros proporcionaban plantones de moreras, con vistas a la cría del gusano de seda, olivos, así como toda clase de frutales, entre los que cabe destacar los cítricos; los principales viveros agrícolas eran los de las Granjas-escuela de Larache y de Melilla. Estas granjas también proporcionan las semillas de cereales así como de numerosas hortalizas. Además, existran viveros forestales en Río Martín, Larache y Segangán.

\section{1.a. Los «perímetros de colonización»}

Uno de los instrumentos importantes para la colonización agrícola en el Protectorado, especialmente para los españoles, fueron los «perímetros de colonización». Las bases para su establecimiento se encuentran en el Dahir de 3 junio 1929 (Boletín Oficial del Protectorado de 25-07-1929), mientras que las instrucciones para su desenvolvimiento fueron fijadas por la Dirección de Colonización el 10-08-192915. La constitución sobre el terreno de tales perímetros de colonización, la realizarían los ingenieros del Servicio Agronómico de la Dirección de Colonización; para ello habían de especificar en la correspondiente memoria la descripción del perímetro a colonizar, la supurficie total, actual estado cultural, posibilidades agrológicas, los trabajos necesarios a realizar tanto por el Majzén como por los particulares para ser puestos en explotación, la situación de los terrenos sobre todo en relación a los centros de consumo y vías de comunicación, posible creación de núcleos de población, beneficios que podrían proporcionar a las economías del país y de la comarca, etc. Asimismo las memorias constitutivas de los perímetros, debían detallar las superficies y propietarios de los terrenos incluidos en el perímetro, con sus correspondientes planos o croquis.

14 AGA, Caja AF-M-1642. Hojas de Información de la Dirección de Colonización, $\mathrm{n}^{\circ}$ 9, septiembre 1929 , Tetuán, $14 \mathrm{pp}$.

${ }^{15}$ AGA, Caja AF-M-1642. 
Atención específica se debía prestar a los terrenos pantanosos o encharcadizos, para proponer su posible saneamiento. En cualquier caso, ante distintos perímetros de colonización, los ingenieros debían priorizarlos para su puesta en cultivo, siempre en relación a los posibles mayores beneficios agrícolas, económicos y sociales, para lo que se valorarían positivamente la mayor superficie del perímetro, el menor gasto para su puesta en cultivo y el plazo de tiempo más corto para ello.

Los perímetros de colonización se establecían sobre superficies incultas o deficientemente explotadas, pero que, a juicio de los técnicos de la Dirección de Colonización, eran susceptibles de ser cultivadas previa ejecución de las mejoras pertinentes (roturación, despalmitado, despedregado, etc, o desecación en el caso de áreas pantanosas). La propiedad de estas tierras podía ser indistintamente del Majzén (lo más frecuente) o de particulares; las primeras podían ser adjudicadas en propiedad, frecuentemente a españoles, mientras la explotación de las segundas correspondía a sus propietarios, y sólo en caso de abandono persistente podían ser adquiridas amistosamente, o incluso expropiadas, por el Majzén, para que éste, a su vez, las pudiese adjudicar a particulares para su explotación. Para iniciar la colonización de estas tierras, la Dirección de Colonización proporcionaba a los propietarios asesoramientos así como útiles de trabajo a precio mínimo. En el caso de desecación de terrenos declarados insalubres -el paludismo era en estos años causa importante de defunciones y de gasto sanitario-, el Majzén subvencionaría a la empresa que hiciera la desecación con un importe no superior al $50 \%$ del presupuesto de estos trabajos; las tierras así saneadas quedarían en propiedad de tal empresa durante 60 años, para revertir después a propiedad del Majzén.

\section{La agricultura en los entornos urbanos: situación en 1930}

En 1929 la Administración española en Marruecos ordenó que las autoridades locales (Intervención Civil Local) confeccionaran memorias mensuales donde se reflejaran «los progresos en los múltiples aspectos que abarca la misión de la Nación Protectora», así como «las deficiencias que se observen en la práctica para irlas subsanando». Las memorias confeccionadas al inicio de 1930 permiten conocer algunos 
datos aproximativos de las situaciones agrícolas locales ${ }^{16}$, en general poco boyantes; estas informaciones se complementan con las coetáneas aportadas por V. Ruiz Albéniz ${ }^{17}$.

Para Villa Sanjurjo (Memoria de enero 1930) se denuncia la falta de cultivo intensivo, asi como el encarecimiento de los productos importados (debido a su desembarco en lanchas por no estar terminado el puerto, así como por impuestos especiales), lo que dificulta la colonización y desarrollo del Rif. Algunos vecinos de esta población han iniciado con éxito el cultivo de la vid, siempre en pequeñas parcelas adquiridas en laderas próximas (Monte Malmusi). Los marroquíes aumentan el cultivo de hortalizas en la vega de Ait Ali, pero sólo un español de Villa Sanjurjo había podido adquirir unas 10 ha. para su explotación intensiva, debido a los elevados precios de estas tierras ${ }^{18}$, hecho que se repite en todo el Protectorado. Se proyecta la constitución de un Sindicato Agrícola integrado por colonos europeos y marroquies, con to que se facilitaría un mayor contacto entre Villa Sanjurjo ${ }^{19}$ y los

${ }^{16}$ AGA, Caja AF-M-1307.

17 Vid. nota 4. Víctor Ruiz Albéniz es autor de numerosas publicaciones sobre el Protectorado de España en Marruecos. En junio de 1930 se celebró en Argel un congreso sobre colonización rural con motivo del centenario de la ocupación de Argelia por Francia, y Ruiz Albéniz fue invitado como ponente sobre la colonización en el Protectorado español. Su aportación fue publicada como libro, cuya ficha es la que figura en la nota 4; en esta monografía se ofrecen el encuadre general de estas actividades, así como su situación y características en aquella fecha.

${ }^{18}$ En esta Memoria se indica que el precio de 1 hectárea de regadío oscila entre 2.000 y 4.000 ptas; como referencia, la Memoria correspondiente a Arcila señala, también para enero de 1930, unos salarios/día de 12 pesetas para albañiles, carpinteros y herreros, entre 5 y 10 pesetas para "obreros" españoles y de 3' 5 pesetas para «obreros indígenas». Algunos precios de productos básicos en Villa Sanjurjo (enero 1930) son: arroz, 0'80 pts $/ \mathrm{kg}$, aceite 2'1, harina 0'70, lentejas 1'50, patatas 0'35, carne de vaca 3'75, pan 0'80.

19 Villa Sanjurjo se fundó en 1925 con el nombre de Villa Alhucemas, en conmemoración del desembarco de tropas españolas en la bahía de Alhucemas, de importancia definitiva contra la insurrección rifeña (vid. Delegación de Asuntos Indígenas. Servicio de Intervenciones, Anuario, Tetuán, junio 1955, fol. 101. (Ejemplar mecanografiado, Biblioteca Nacional de Madrid). 
poblados musulmanes más cercanos, $\mathrm{y}$, consiguientemente, la mejora agrícola de la comarca.

En 1930, según Ruiz Albéniz, Villa Sanjurjo contaba con 2.628 habitantes, casi todos españoles, pues los marroquies eran 140 y 12 los hebreos, pero los trabajos de colonización rural protagonizados por españoles en la vega de Alhucemas se desarrollan precisamente a partir de 1930; en esta vega, que cuenta con el agua de los ríos Nekor y Guis, estaba prevista una extensión regable de 9.000 hectáreas ${ }^{20}$. Un oficio

${ }^{20}$ Ruiz Albéniz V., Ob. cit., pp. 35-36 y 108-110. Sobre la población indicada por este autor, la Memoria del Interventor Civil señala una población escolar de 438 niños, lo que resalta una estructura demográfica equilibrada en este núcleo.

Aunque el nacimiento de Villa Sanjurjo conmemora un hecho militar, su situación es totalmente distinta al resto de nuevos poblados españoles del Protectorado cuya vida se inició en torno a campamentos militares. Villa Sanjurjo es el único núcleo que nace planificado y con vocación de ciudad, en concreto como futura capital del Rif, pues centralizaría un área notablemente poblada, desprovista de ciudades y equidistante de los alejados centros urbanos situados al este (Melilla) y oeste (Tetuán, Ceuta, Larache); la construcción de un puerto en Villa Sanjurjo y las posibilidades de amplios terrenos de regadío en su entorno, son factores económicos que se suman a los estratégicos. Según las Memorias del Interventor Civil de enero y febrero de 1930 (vid. nota 16), las obras del puerto de Villa Sanjurjo están avanzadas, junto con otras importantes obras públicas, como un grupo escolar de 6 aulas, la avenida entre el puerto y el núcleo urbano, dos depósitos de agua (marina) para uso público, cementerio, obras de urbanización, así como distintas obras militares (hay dos cuarteles). Todo ello explica el rápido crecimiento inicial de este núcleo, tanto en población -2.628 habitantes en 1930- como en edificación, pues en este año ya se citan tas siguientes calles: General Gómez Jordana, La Paz, Zabala, Rodríguez Besconsa, Alférez Nava, Avda. 23 de septiembre, General Primo de Rivera, Melilla, Alhucemas, avenida de Alfonso XIII, y las plazas de España (donde se ubica la iglesia parroquial regentada por franciscanos, así como el grupo escolar en construcción), del Rif y del Mercado; también se cita el paseo de la Marina, junto al mar. Como ciudad nueva, donde se han emprendido numerosas obras públicas, se hace notar la "inmigración de aluvión", que da lugar a «multitud de barracas, antiestéticas», localizadas en las laderas de Cala del Quemado, para las que se propone su traslado al Barrio Obrero. Esta situación inicial de Villa Sanjurjo supone obviamente dificultades económicas y de empleo, toda vez que la colonización agrícola de la vega de Alhucemas aún no se ha desarrollado; así, las Memorias denuncian la proliferación antieconómica de comercios (190 en enero de 1929, 274 en febrero de 1930), la carestía de la vida (25\% superior a Melilla), o los graves problemas de paro que origina la suspensión -por falta de créditos- de las 
del Inspector General de Intervención fechado en Tetuán el 21-9$1929^{21}$ señala que se ha modificado el sistema actual de riego en el Llano de Beni Urriaguel o vega de Alhucemas para evitar el encharcamiento de las aguas, y que se disponía de un crédito de 4 millones de pesetas para sanear sus zonas pantanosas y ponerlas en cultivo; asimismo especifica que la Dirección de Colonización, en aquella fecha, ya tenía hecho el estudio para sanear y colonizar la vega de Alhucemas.

Nador, al sur de Melilla, es un núcleo nacido al amparo de los campamentos militares españoles establecidos alli en 1908, aunque hasta 1915 no se creó la primera Junta de Arbitrios y en 1930 la Junta de Servicios Municipales, pero será a partir del inicio de la guerra civil cuando desarrolla su mayor crecimiento $^{22}$. La Memoria de 1930 redactada por el Interventor civil señala para los alrededores de Nador un suelo cultivado de unas 1.000 ha. de secano, de cereales, a los que falta maquinaria agrícola moderna, 22 ha. de viñedo y unas 100 ha. de huertas, que en parte abastecen a Melilla; la Memoria denuncia la falta de estímulo oficial a uestos humildes y abnegados hortelanos». Los colonos españoles residentes en Nador también distribuyen sus explotaciones en pueblos de la comarca, como Segangán y otras aldeas.

En las cercanías de Nador, los poblados de Segangán, Monte Arruit, Zaio, Zeluán y Karia de Arquenán están habitados fundamentalmente por españoles, con censos que en 1935 oscilan entre 837 habitantes para el primero y 131 en el último ${ }^{23}$, en buena parte dedicados a la agricultura. Su evolución económica no fue fácil, ya que entre 1935 y 1955 parte de ellos -Zeluán, Karia de Arkenán- reducen fuertemente su población española, cuando el conjunto del Protectorado

obras militares en febrero de 1930 , que afectó a 162 obreros españoles, y a 198 marroquíes. La actividad económica industrial de Villa Sanjurjo se reducía a la fábrica de electricidad, 3 panaderías, 1 serrería mecánica y 1 talîer de mecánica. Una grave carencia en estas fechas es la de las carreteras.

21 AGA, Caja AF-M-1642.

22 Delegación de Asuntos Indígenas. Servicio de Intervenciones, Anuario. Tetuán, junio 1955, fol. 87 (mecanografiado).

23 Gozálvez Pérez, V., "Descolonización y migraciones desde el África española (1956-1975)», Investigaciones Geográficas, $\mathrm{n}^{\circ} 12$, Universidad de Alicante, 1994, pp. 45-84. 
la multiplica por $\operatorname{dos}^{24}$. Todos los núcleos indicados tienen su origen en campamentos militares establecidos durante la ocupación del Protectorado ${ }^{25}$.

Targuist se localiza en el interior del Rif, y debe su desarrollo -426 habitantes en 1930- al voluminoso campamento de tropas españolas establecido allí en 1926. La actividad comercial de los españoles está en declive por la disminución de la guarnición española, aunque existe la esperanza de mejora con la futura colonización agrícola y el desarrollo comercial $^{26}$.

Las regiones occidentales del Protectorado son las de mayores posibilidades para la colonización agrícola, favorecidas tanto por la pluviometría, cursos fluviales -ríos Lucus y Martín- y espacios llanos con buenos suelos, como por la relativa abundancia del poblamiento urbano y de comunicaciones.

El entorno de Larache se presenta como una de las comarcas del Protectorado con mejores condiciones naturales para la colonización agrícola; de hecho allí se encontraba la Granja de Larache, que regentaba la Administración española, para alumnos marroquíes, así como el domicilio social de la mayor empresa privada de colonización, la Compañía Agrícola del Lucus, S.A., fundada en 1921 con 8 millones de pesetas de capital nominal ${ }^{27}$, aunque, además de su actividad agrícola también desarrolló empresas industriales, pues en 1930 ya trabajaba con una fábrica de harinas en Larache, al mismo tiempo que

${ }^{24}$ Ruiz Albéniz, V., Ob. cit., pp. 116-117.

25 Delegación de Asuntos Indígenas. Servicio de Intervenciones, Anuario, Tetuán, junio 1955, fol. 87 (mecanografiado).

${ }^{26}$ Ruiz Albéniz, V., Ob. cit., p. 115. AGA, Caja AF-M-1307. Delegación de Asuntos Indígenas. Servicio de Intervenciones, Anuario, 1955, fol. 102 (mecanografiado). Tres hechos indicados en la Memoria del Interventor Local (febrero de 1930) ilustran sobre la situación de Targuist: a) se recomienda que los propietarios de las casas construyan pozos negros, pues la mayoría de éstas carece de retrete; b) hasta la fecha se carece de escuela; c) las casas de lenocinio proporcionaban la cuarta parte de las recaudaciones del Interventor $\mathbf{( 3 . 8 4 2}$ pesetas). Un censo fechado el 13-XI-1931, señala para Targuist 500 habitantes civiles y 1.600 militares (AGA, Caja AF-M-1642).

${ }^{27}$ Morales Lezcano, Víctor, España y el norte de Africa: el Protectorado en Marruecos (1912-56), Madrid, UNED, 1984, p. 189. 
solicitaba autorización para establecer una fábrica de conservas vegetales $^{28}$. En 1930 esta empresa de colonización se cita como la única de esta región que posee una gran propiedad, la finca El Adir, de más de 1.000 hectáreas, localizada en el entorno de Larache, donde contaba con grandes posibilidades de regadfo a partir del río Lucus. También en la zona de Larache existían varias explotaciones considerables -en torno a 500 ha.-, así como otras más reducidas y numerosas, con frecuencia de regadío, formadas a partir de tierras del Majzén ${ }^{29}$.

En Arcila, también en la costa atlántica, la Memoria del Interventor (enero de 1930) señala que «dentro del radio de acción de esta Intervención casi no existe agricultura» aunque en la ciudad residían 895 españoles -sobre un total de $\mathbf{4 . 5 6 5}$ habitantes-, entre ellos los agricultores concesionarios del predio de colonización del Handekien (finca de 785 ha., a unos dos $\mathrm{km}$ de Arcila, parcelada por el Estado en 13 lotes de extensión variable) ${ }^{30}$.

La Memoria sobre Alcazarquivir, importante mercado agrícola, tanto de cereales como ganadero, señala relativa buena situación para su agricultura y colonización, en parte debido al buen funcionamiento de un Pósito Agrícola; entre las industrias de la ciudad relacionadas con la agricultura, en 1930 se censan una fábrica y cinco molinos de harinas, así como un molino aceitero recién inaugurado. No obstante, las posibilidades agrícolas con regadío del Lucus todavía están lejos de alcanzar plena producción ${ }^{31}$.

Las Memorias (diciembre 1929 y marzo 1930) sobre la ciudad interior de Chauén señalan aumento paulatino de la producción agrícola,

28 AGA, Caja AF-M-1307.

${ }^{29}$ Ruiz Albéniz, V., Ob. cit. La atracción de Larache para los trabajadores españoles fue muy considerable, pues en 1924 se presenta un proyecto para construir una «barriada de casas económicas para obreros» españoles, todas de planta baja y con jardín; según la memoria de este proyecto eran unas 500 familias españolas residentes en Larache las que necesitaban vivienda, pues ocupaban barracas -más de 200 - o casas muy deficientes -unas 300-; también se propone plano especial para algunas de las casas al objeto de acoger a robreros que carezcan de familia (AGA, Caja AF-M-1438).

${ }^{30}$ AGA, Caja AF-M-1307. Ruiz Albéniz, V., Ob. cit. pp. 95 y 143.

${ }^{31}$ AGA, Caja AF-M-1307. Ruiz Albéniz, V., Ob. cit. pp. 101 y 144. 
tanto de cereales como de verduras (regadío), debido a la modernización en los trabajos agrícolas que van introduciendo los marroquíes; en estas fechas se acaba de inaugurar un moderno molino aceitero que complementa a los tradicionales marroquíes; su situación en el interior del Protectorado y la deficiencia de las comunicaciones, han dificultado el establecimiento de colonos españoles ${ }^{32}$.

El río Martín, que propició importantes regadíos en el entorno de Tetuán, rodeaba su desembocadura de terrenos inundables que en 1930 estaban en fase de colonización a partir del núcleo Río Martín, situado en su desembocadura, a unos $10 \mathrm{~km}$ de la capital ${ }^{33}$. Según la Memoria del Interventor -febrero de 1930-, la zona de cultivo de Río Martín se reduć́a a terrenos del Majzén arrendados a un español, que, a su vez, había instalado a unos 40 colonos, de los que 11 eran marroquíes y el resto españoles; los cultivos eran sobre todo los propios de huerta

${ }^{32}$ En efecto, en 17-IX-1931 el Interventor local de Chauén notifica al Alto Comisario la carencia de comunicaciones en que se encuentra la ciudad, lo que dificulta el comercio y trabajo de la localidad «que siempre fue centro industrial -textil- y comercial de toda esta región». Por otra parte, el 27 de julio de 1931 la colonia española en Chauén dirige un escrito al Alto Comisario de España en Marruecos, en el que se describe una situación más que deplorable de la ciudad; así, piden 1) que se canalicen las aguas potables; 2) que se construyan un colector para las aguas sucias y un cementerio; 3) que se dote la plaza de médico y practicante; 4) que se construya un enlace de carretera de Chauén con la general de Melilla; 5) Que se clausure el matadero viejo por higiene; 6) protección para la industria y comercio, en especial que se prohiba a las tropas del Campamento la fabricación de ladrillos pues perjudica a los industriales; 7) que la Barriada del Campamento pase a depender de la Junta Municipal y no del Sector Militar; 8) que se cree el Juzgado Municipal, y 9) que se clausuren casas de prostitución "pues en la actualidad existe un número tan crecido que se encuentran instaladas en el centro de la población». (AGA, Caja AF-M-1354).

${ }^{33}$ El núcleo de Río Martín, cuya playa fue desde antiguo lugar de veraneo para los tetuanies, en 1931 censaba 1.277 habitantes, de los que 641 españoles (Ruiz Albéniz, V., Ob. cit., p. 111), mientras fue durante los años 1920 cuando amplió notablemente su censo, pues menudean las solicitudes de españoles para ocupar las amplias parcelas -entre 500 y $300 \mathrm{~m}^{2}$ - de su Plano de urbanización; muchos edifican primero barracas, que después tranforman en casas de mampostería. Estas parcelas, igual que los terrenos de colonización, eran propiedad del Majzén (AGA, Caja AF-M-1438). 
-patatas, pepino, tomate, sandra, etc.- aunque con rendimientos aún medianos $^{34}$.

Los ejemplos aportados, pese a su escasa información, además de carácter general, sin duda confirman el estadio inicial de la colonización agrícola española en los años que siguen a la pacificación del protectorado. En estos años la Administración española -Dirección de Colonización- intentaba impulsar el establecimiento de colonos a través de los llamados "Perímetros de colonización". Ya se ha indicado la escasez de tierras en venta y el minifundismo generalizado entre los propietarios autóctonos, lo que dificulta en extremo tales establecimientos de españoles. Ante esta situación se intenta delimitar y colonizar - "perímetros de colonización»- las tierras de titularidad pública, o del Majzén, formadas en parte por las áreas palustres, sobre todo litorales, lo que, aparte de su aprovechamiento agrícola, repercutfa muy positivamente en la erradicación del paludismo. Además de esta incipiente colonización oficial, la pacificación de 1927 también supuso un gran impulso a la colonización "libre"; así, Ruiz Albéniz señala que con esta modalidad los españoles, en 1930, cultivan 11.305 hectáreas en la región Oriental y 9.888 en el centro y occidente del Protectorado ${ }^{35}$.

En cualquer caso, los problemas de superviencia de los colonos agrícolas españoles, fundamentalmente debido a su descapitalización, también parecen acuciantes en estos años. En efecto, durante la segunda mitad del año 1935 los colonos redactaron varios escritos de denuncia que dirigieron a las Autoridades españolas. Tales acciones parece que se inician en una reunión de 19 septiembre de 1935 realizada en la colonización de Handekién (Arcila), en la explotación de un influyente colono, ingeniero agrónomo, a la que asistieron varios representantes de sindicatos agrícolas, así como el director de la Gaceta de África; se trató de la falta de apoyo de las autoridades españolas ante la difícil situación de los colonos españoles en el Protectorado, por lo que acuerdan solicitar el reembolso de las cantidades invertidas en la mejora de sus explotaciones de Handekién, a fin de trasladarse a otros lugares, muy posiblemente al vecino Protectorado francés. Dichos acuerdos

\footnotetext{
${ }^{34}$ AGA, Caja AF-M-1307.

${ }^{35}$ Ruiz Albéniz, V., Ob. cit. pp. 144-146.
} 
fueron trasladados por el Sindicato Agrícola de Arcila (21 de septiembre) al Alto Comisario de España en Marruecos. En este escrito, además de lo indicado, se menciona expresamente la excesiva recaudación de impuestos que padecen los colonos, mientras las explotaciones están en periodo de transformación, así como la necesidad de garantizar cierto nivel de precios para la producción de los colonos, toda vez que el vecino Protectorado francés había prohibido las importaciones desde el Protectorado español. Este escrito parece fue publicado en los diarios ABC y El Sol, de Madrid, al mismo tiempo que se pretendía llevar el tema al Congreso de Diputados.

El 30 de septiembre de 1935 el Sindicato Agrfcola de Rincón del Medik también elaboro otro escrito similar, en el que asimismo denuncia la falta de atención de las autoridades españolas a sus problemas. A los anteriores se uniría, con fecha 30 octubre de 1935 la Federación de Sindicatos Agrícolas de la Región Oriental. Esta Federación insiste en la falta de apoyo a los colonos por parte de las autoridades españolas y especificamente menciona las amenazas de embargo y confiscación de las tierras de los colonos ante su imposibilidad de reembolsar con puntualidad los préstamos del Pósito Agrícola; por todo ello piden al Alto Comisario de España en Marruecos que el Majzén tome posesión de dichas explotaciones -previo pago de las mejoras hechas por los colonos- "para dedicarnos a otras actividades» ${ }^{36}$.

\section{Los colonos españoles en 1943}

Durante los años que siguen a la guerra civil, el Protectorado español sufre acusadas carestías por obvias razones de presupuestos y

36 AGA, Caja AF-M-1354. La Federación de Sindicatos Agrícolas de la Región Oriental, según el escrito comentado de 30 octubre de 1935, estaba formada por: los sindicatos agrícolas hispano-indígenas de Nador, de Zeluán, de Zaio y de Quebdana, así como los sindicatos agrícolas de Garet y de Drius.

Sobre el número de colonos que propician estas denuncias, en la documentación consultada sólo se especifica para Rincón de Medik, con 22 colonos, aunque esta cifra no incluye a la totalidad de los de este núcleo. Por otra parte, se indica que el escrito inicial de los colonos de Arcila, debía llegar a los de Río Martín y Castillejos. 
de déficit de autoabastecimiento, a su vez agravado por la sequía. Como resultado, el 1 de noviembre de 1940 se decretó el racionamiento de alimentos básicos en los núcleos urbanos, mientras se producía una intensa emigración de campesinos marroquíes hacia el vecino Protectorado francés. Para aliviar tan grave situación socieconómica, en 1940 las autoridades españolas proponen, especialmente para la más árida región oriental del Protectorado, a) reanudar los trabajos en pistas y carreteras, b) reducir algunos impuestos, y c) el aumento del regadio $0^{37}$. En esta situación, durante 1941 se suceden los informes de las autoridades españolas sobre la emigración clandestina de familias marroquíes hacia el vecino Protectorado francés; así, el Interventor Regional de Nador, en escrito de 1 de octubre de 1941 señala las dificultades para conocer esta emigración, aunque la evalúa en 713 familias -entre 5 y 8 personas por familia- más otros 3.000 emigrantes individuales. También se denuncia parecida emigración en la zona fronteriza cercana a Alcazarquivir ${ }^{38}$.

En tal contexto de dificultades económicas, a principios de 1943 las autoridades españolas del Protectorado -por medio del Delegado de Asuntos Indígenas- deciden conocer en detalle la situación de los colonos españoles, al mismo tiempo que impulsar un mayor número de asentamientos de colonos diseminados geográficamente, con la pretensión de «que sirvan de maestros a los indígenas de la localidad» y así aumentar la producción agrícola ${ }^{39}$.

El conocimiento de la situación económica de los colonos españoles se realizarf́a mediante la confección de una ficha individual por parte de los Interventores, en la que debía constar: fecha del establecimiento, lugar, localización y superficie de las parcelas, si son de secano o de regadío, condiciones en que se realizan sus trabajos de colonización, si la explotación es en propiedad o en arrendamiento, condición de los

${ }^{37}$ AGA, Caja AF-M-2416.

${ }^{38}$ AGA, Caja AF-M-2417. El contrabando de cebada desde el Protectorado francés hacia el español, parece que facilita en el sur el empleo agrícola para los emigrantes que llegan del norte.

${ }^{39}$ AGA, Caja AF-M-2354. La intención de mejorar la producción de los agricultores marroquíes con el ejemplo de colonos españoles, es una constante que se repite en las autoridades españolas del Protectorado desde décadas anteriores. 
aperos de labranza, si la cosecha quedaba íntegra para el colono o en su caso han de entregar parte a los propietarios. La información que debía recoger este censo se da a conocer en oficio fechado en Tetuán el 13-02-1943; en diciembre del mismo año las autoridades locales remitían la documentación solicitada ${ }^{40}$. Las fichas consultadas generalmente aportan todos los datos básicos indicados, aunque en algunos territorios se ofrecen de forma incompleta.

\section{3.a. Los colonos españoles como agentes de enseñanza agrícola}

La vieja política de aumentar la red de colonos asentados, con finalidad didáctica y de estímulo para el agricultor marroquí, es de nuevo propuesta en 1943. Ante la consulta, el parecer de los Interventores de Territorio es variado. Así, para el Rif no se aconseja el establecimiento de mayor número de colonos -ya escasos- debido a las limitaciones naturales para la agricultura (terrenos pedregosos, altitud). Para el Quert, en cambio, la idea parece excelente, igual que para el territorio de Chauén "siempre que los colonos fueran competentes». También parece positiva la idea al Interventor del Lucus, donde los colonos españoles incluso podrían establecerse en régimen de aparcería con agricultores marroquíes ucomo el mejor sistema para reportar enseñanzas al indígena». Para el caso de Yebala la idea propuesta se estima en principio conveniente, pero en la práctica se ve dificultada debido a la escasez de terrenos de regadío. Finalmente, el Delegado de Asuntos Indígenas, Sección Política, al resumir (con fecha 30-01-1943) los distintos pareceres de los Interventores, resalta la dificultad para adquirir terrenos de buena calidad a propietarios marroquíes, mientras «la práctica aconseja huir del arriendo de terrenos al indígena y yemás; tampoco es recomendable el trabajo de aparcerfa con el indígena, bajo el punto de vista psicológico, político y moral». Lo deseable es, una vez más, el asentamiento de españoles en terrenos del Majzén, siempre que estos reúnan posibilidades de regadío, y se evite el excesivo aislamiento del colono. En cualquier caso, debe ser el Majzén quien adquiera los terrenos, y una vez parcelados y con las viviendas construidas, se debe

${ }^{40}$ AGA, Caja AF-M-2354. 
arrendarlos a colonos, que después de un periodo de explotación de 2025 años pasarían a ser propietarios.

\section{3.b. Distribución geográfica de los colonos, fecha de su estableci- miento y lugar de procedencia}

Según la información que analizamos, fechada en diciembre de 1943, había 304 colonos españoles, titulares de explotaciones, en los territorios del Protectorado de España en Marruecos (vid. cuadros). Su distribución geográfica es irregular, con claras concentraciones en los extremos: así, en la región oriental -Quert- se localizan casi la mitad, 145, distribuidos fundamentalmente en cinco núcleos de fundación española, nacidos al calor de los campamentos militares ${ }^{41}$, es decir Nador con 30 colonos, Segangán 8 colonos, Zeluán 8 colonos, Monte Arruit 54 colonos y Zaio 13 colonos; en estos momentos todos estos núcleos tienen una población mayoritariamente española (vid. mapa) ${ }^{42}$, entre los que se encuentran buen número de jornaleros de los colonos. Como se observa en el cuadro V, el Quert es la región del Protectorado donde primero, y más regularmente, se establecen los colonos españoles, pues entre los que perviven en 1943, los hay que se establecieron desde el mismo momento de la delimitación política de fronteras (1912), y en cada uno de los años posteriores; esta regularidad de establecimientos, que incluso se extiende a los años 1904-09, sin duda está conexionada con la seguridad que proporcionan las vecinas tropas españolas de Melilla y de Nador, pues en la segunda localidad ya se instalaron en 1908 al mando del general Marina ${ }^{43}$.

Las fichas de los colonos de la región de Quert son las únicas que proporcionan información bastante completa sobre el lugar de procedencia; los datos del cuadro VI confirman afirmaciones genéricas ya

41 Delegación de Asuntos Indígenas. Servicio de Intervenciones, Anuario, Tetuán, junio de 1955, 505 pp. (mecanografiado, ejemplar en Biblioteca Nacional, Madrid), Cfr. pp. 85-87.

42 Gozálvez Pérez, V., "Descolonización y migraciones desde el África española (1956-1975)", Investigaciones Geográficas, n. 12, 1994, pp. 45-84, cfr. pp. 74-75.

${ }^{43}$ Vid. nota 41. 
conocidas, al destacar los oriundos de los pueblos de las provincias de Almerf́a y Murcia, seguidas de Granada y Málaga, aunque los colonos españoles que se trasladan desde el vecino Oranesado son los más numerosos.

Las regiones occidentales de Yebala y Lucus censan, respectivamente, 68 y 67 colonos. Aunque en Tetuán reside el contingente más numeroso de españoles -22.103 en 1940, 29.004 en 1945-, los colonos agrícolas de Yebala viven mayoritariamente en Castillejos (cuadro II), núcleo de fundación española que en 1940 censa 925 españoles, que constituyen el 88\% de su población total. Rincón del Medik (813 españoles en 1940) es la segunda localidad en número de colonos (cabila El Hauz). En el Lucus, los colonos se distribuyen en las ciudades de Alcazarquivir, que acapara la mitad (33) de los colonos, en Arcila, con 22, y en Larache, con 12; en estas tres ciudades la población mayoritaria es marroquí, aunque con importantes colonias españolas, que en 1940 alcanzaban 11.568 en Larache, 3.559 en Alcazarquivir y 1.335 en Arcila. Como detalla el cuadro V, el establecimiento regular de colonos en Yebala data de 1916, mientras para el Lucus no llega hasta 1924, sin duda debido a su ocupación militar más tardía, ya que agrícolamente ésta es la región con mejores posibilidades; lo último en parte también se patentiza por las acumulaciones de colonos que se registran aqui en algunos años $(1928,1935, \ldots)$.

Finalmente en el Rif y Chauén los colonos censados en 1943 son muy escasos, y con fechas de establecimiento mucho más tardía, casi todos después de 1930. El contingente más numeroso -14 colonos- es el que coloniza la vega de Alhucemas, a partir de la fundación de Villa Sanjurjo.

\section{3.c. La estructura de las explotaciones}

La superficie disponible por los colonos suma, en 1943, 24.902 hectáreas, de las que 23.180 eran de secano, 590 de regadío y 1.131 son calificadas de "regadío y secano». No obstante conviene destacar que las superficies de secano (93\% del total), en fuerte proporción eran superficies incultas, según la documentación consultada: «los colonos poseen bastantes tierras sin cultivar, hay terrenos estériles y de monte bajo... Queda mucha tierra sin cultivar de la que poseen los colonos», 
sobre todo en el Quert, aunque en parte utilizada para el ganado ovino que poseen muchas de las explotaciones agrícolas de Monte Arruit, con rebaños entre 50 y 500 cabezas.

Aunque el $93 \%$ de la superficie total era de secano, tal proporción disminuye al $86 \%$ en el Lucus, y sólo al tercio en las escasas superficies que poséáan los colonos de Chauén y del Rif (cuadro I), dados los especiales y tardfos establecimientos en estas dos regiones. Las mayores superficies absolutas de regadío pertenecen a las regiones de Quert y Lucus, aunque la vega de Alhucemas también proporciona una superficie considerable (cuadros I y II). El regadío se distribuye sobre la mayoría de las explotaciones, bien en pequeñas parcelas hortícolas, frecuentemente alimentadas con pozos, sobre todo en la región de Quert, bien en parcelas incluso de varias hectáreas en la vega de Alhucemas o que aprovechan las aguas de los ríos Muluya y Lucus.

De acuerdo con la política propugnada por las autoridades españolas del Protectorado, la propiedad de la tierra es el régimen de tenencia preponderante en el Quert (93\%), la región donde más abundan y más tempranamente se establecieron los colonos españoles. En el resto de regiones el porcentaje de tierras en propiedad disminuye con la menor antigüedad de los establecimientos $-72 \%$ en Lucus, $16 \%$ en el Rif-, o con la mayor densidad de población marroqui $-51 \%$ en propiedad en Yebala-, dado el conocido y lógico rechazo a la venta de tierras por parte del propietario autóctono. En esta misma tendencia política de separación entre españoles y autóctonos en lo que concierne a tierras de cultivo, la propiedad de las tierras arrendadas por los colonos españoles, 2.940 hectáreas, sólo una extensión insignificante tenía titular marroquí -15 ha. en Arcila-, mientras la mayor parte pertenecía a otros españoles -1.656 ha.- o al Estado (cuadro III).

La distribución de las explotaciones por superficie se ofrece en el cuadro IV. La primera característica es el minifundismo, ya que el $41 \%$ de las explotaciones tienen menos de 5 hectáreas, y el $60 \%$ menos de 20 ha.; además, al minifundismo por superficie se añade el minifundismo económico, ya que, como hemos visto, el predominio pertenece al secano. La superficie mucho más extensa que poseen los colonos españoles en la región de Quert, con 20.824 hectáreas sobre un total de 24.902 en todo el Protectorado, se explica por la concentración en esta región de 6 explotaciones con más de 500 ha. y suma de 14.896 ha.; 
entre éstas, la mayor registra 11.282 ha., propiedad de la Compañfa Española de Colonización ${ }^{44}$; de estas explotaciones mayores, cuatro pertenecen a colonos de Monte Arruit, y son casi en su totalidad de secano. La mayor propiedad agrícola del Lucus, con 637 hectáreas, también es de secano y tiene como titular a "Cultivos y Obras, S.A.".

\section{3.d. Los cultivos}

Los cultivos más importantes en las explotaciones de los colonos, siempre según las fichas confeccionadas en 1943, son, obviamente, los cereales, especialmente cebada, pero en todas las regiones se consignan las hortalizas; entre los frutales, también en regadío, no se especifica cuáles, excepto los cítricos, más abundantes en el Lucus, ya que en Quert y Yebala se especifica «algunos naranjos y limoneros». Olivos y viñas sólo se consignan en Quert; en esta región también se censa como colono la "Algodonera Marroquí, S.A.», establecida en Midar (año 1940), con una explotación de 167 hectáreas, para cultivar algodón. Para el Rif se informa de dos plantaciones singulares: una es de 79 hectáreas de caña de azúcar, aunque fue abandonada después de la siembra; la segunda son 35 hectáreas de ricinos para la obtención de aceites y grasas.

\section{3.e. Situación económica de los colonos}

Las dificultades económicas de los colonos españoles quedan explícitas en la información recogida en 1943 (cuadro II), cuando se califica la condición económica de este agricultor. Para un total de 111 colonos (36\% del total), sólo $32(29 \%)$ gozarían de buena situación económica, 43 la tendrían uregular» y para $36(32 \%)$ es calificada de "mala»; cifras, pues, que confirman otras afirmaciones -genéricas o nosobre la mediocridad económica, o poco favorable, en que se desenvolvía el colono del Protectorado español ${ }^{45}$. En este apartado son los de Yebala y el Lucus los mejor conocidos: destaca la mayor pobreza de los

\footnotetext{
${ }^{44}$ Compañía fundada en 1915 (vid. nota 7 ).

${ }^{45}$ Gozálvez Pérez, V., Ob. cit., pp. 74-80.
} 
colonos de Yebala, pues para el $44 \%$ se especifica mala condición económica, mientras los del Lucus son los mejor parados, sobre todo por el $52 \%$ de los que gozan de condición económica "regular»; entre estos últimos, los 33 colonos de Alcazarquivir son los que disfrutan de mejor posición, pues la calificación se reparte por mitad entre «buena» y "regular", para lo que cuentan con una notable proporción de superficie de regadío (cuadro II), mayor pluviometría que en el resto de regiones, y una estructura de las explotaciones que desecha el minifundismo acusado: en la categoría de hasta 10 hectáreas sólo se encuentran el $18 \%$ de las explotaciones, entre 10 y 50 ha., el $66 \%$, y otro $15 \%$ poseen entre 50 y 200 hectáreas. 


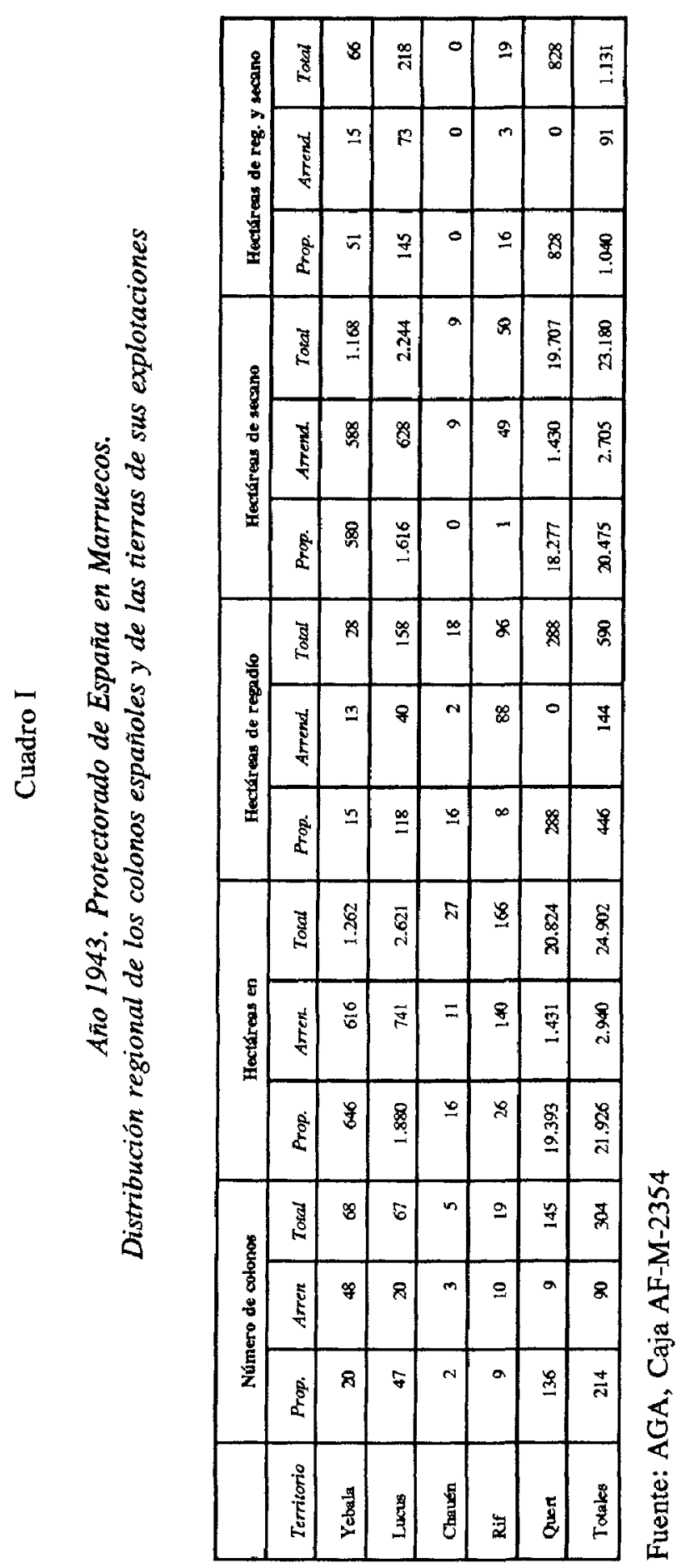




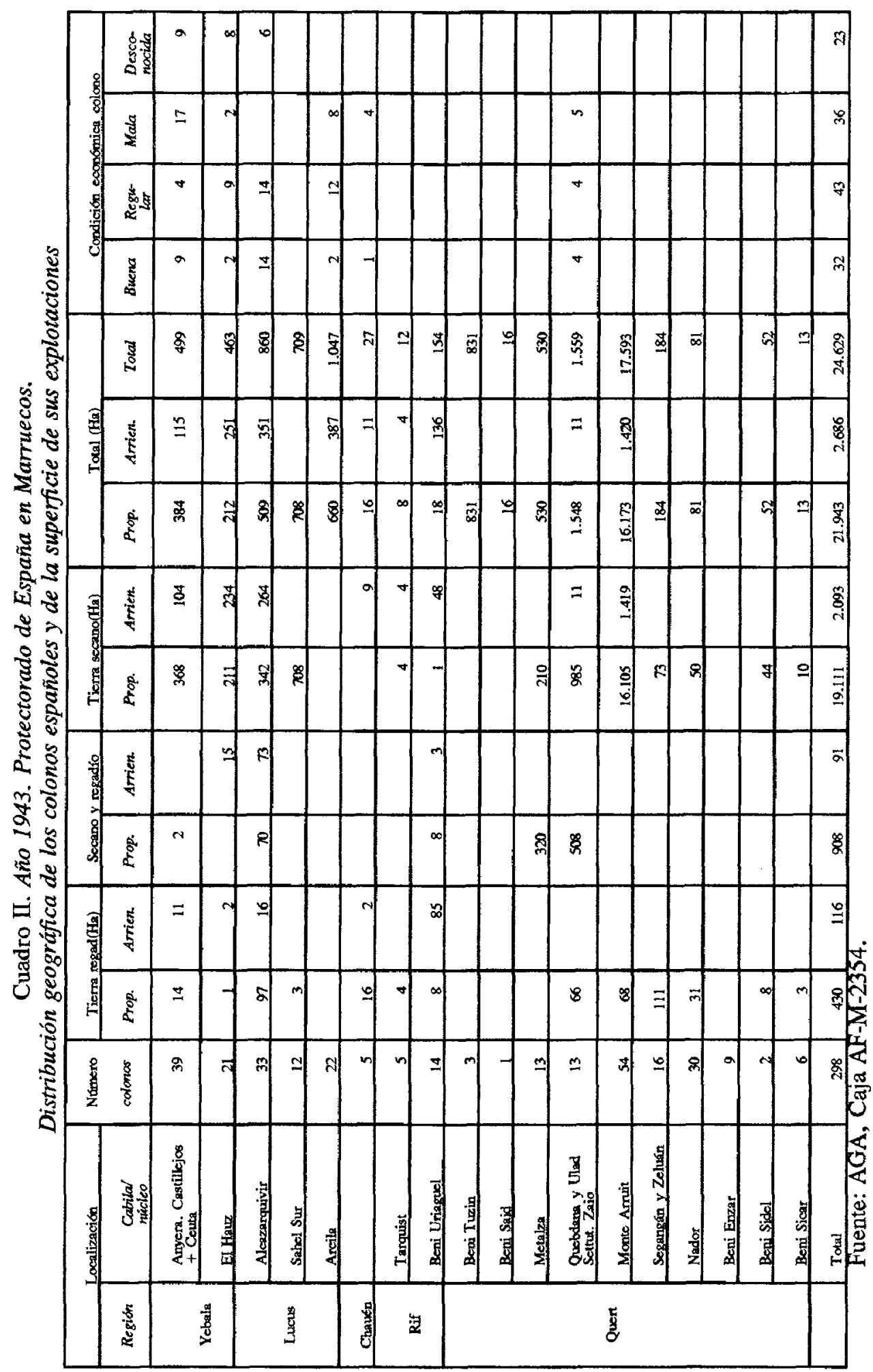




\section{Cuadro III}

Año 1943. Protectorado de España en Marruecos.

Propietarios de las tierras arrendadas por los colonos españoles

\begin{tabular}{|l|r|r|r|r|}
\hline Propietario & \multicolumn{1}{l|}{$\begin{array}{l}\text { Hectá- } \\
\text { reas }\end{array}$} & regadío & secano & \multicolumn{1}{c|}{$\begin{array}{l}\text { regadio } \\
\text { secano }\end{array}$} \\
\hline Majzén & 484 & 106 & 310 & 67 \\
\hline Servicio de Montes & 35 & & 35 & \\
\hline Estado Español & 120 & 15 & 105 & \\
\hline Oficinas de Intervención & 1 & 1 & & \\
\hline Habús & 22 & 1 & 16 & \\
\hline Españoles & 1.656 & 1 & 1.655 & \\
\hline Marroquíes & 15 & & 15 & 91 \\
\hline Indeterminados & 355 & 19 & 333 & \\
\hline Totales & 2.940 & 144 & 2.705 & \\
\hline
\end{tabular}

Fuente: AGA, Caja AF-M-2354 
Cuadro IV

Año 1943. Protectorado de España en Marruecos. Distribución de los colonos españoles según la superficie de sus explotaciones

\begin{tabular}{|c|c|c|c|c|c|c|}
\hline & \multicolumn{6}{|c|}{ Número de colonos en } \\
\hline Hectáreas & $\begin{array}{l}\text { Ye- } \\
\text { bala }\end{array}$ & Lucus & Chauen & Rif & Quert & Total \\
\hline $0-1$ & 15 & 2 & 1 & 2 & 16 & 36 \\
\hline $1,1-5$ & 27 & 18 & 2 & 11 & 31 & 89 \\
\hline $5^{\prime} 1-10$ & 3 & 6 & 1 & 3 & 19 & 32 \\
\hline $10^{\prime} 1-20$ & 1 & 14 & 1 & 1 & 10 & 27 \\
\hline $20 ' 1-50$ & 12 & 18 & & 1 & 15 & 46 \\
\hline $50 \prime 1-100$ & 4 & 5 & & 1 & 9 & 19 \\
\hline $100^{\prime} 1-200$ & 2 & 1 & & & 15 & 18 \\
\hline $200^{\prime} 1-500$ & 1 & 2 & & & 13 & 16 \\
\hline $500^{\prime} 1-1.000$ & & 1 & & & 4 & 5 \\
\hline $\begin{array}{l}1.000^{\prime} 1- \\
2.000\end{array}$ & & & & & 1 & 1 \\
\hline $\begin{array}{l}\text { Más de } \\
10.000\end{array}$ & & & & & 1 & 1 \\
\hline Sin clasificar & 3 & & & & 11 & 14 \\
\hline Totales & 68 & 67 & 5 & 19 & 145 & 304 \\
\hline
\end{tabular}

Fuente: AGA, Caja AF-M-2354 


\section{Cuadro V}

Año 1943. Colonos españoles en el Protectorado de España en Marruecos: Distribución por regiones y año de establecimiento

\begin{tabular}{|c|c|c|c|c|c|c|}
\hline Año de establecimiento & Yebala & Lucus & Chauén & Rif & Quert & Total \\
\hline 1904 & & & & & 1 & 1 \\
\hline 06 & & & & & 1 & 1 \\
\hline 07 & & & & & 1 & 1 \\
\hline 09 & & & & & 1 & 1 \\
\hline 1912 & 1 & 1 & & & & 2 \\
\hline 13 & & 1 & & & 2 & 3 \\
\hline 14 & & & & & 1 & 1 \\
\hline 15 & & & & & 2 & 2 \\
\hline 16 & 1 & & & & 8 & 9 \\
\hline 17 & 1 & 2 & & & 2 & 5 \\
\hline 18 & 1 & 1 & & & 10 & 12 \\
\hline 19 & & & & & 1 & 1 \\
\hline 1920 & 3 & & & & 4 & 7 \\
\hline 21 & 2 & & & & 1 & 3 \\
\hline 22 & 4 & & & & 1 & 5 \\
\hline 23 & 3 & & & & 6 & 9 \\
\hline 24 & 1 & 1 & & & & 2 \\
\hline 25 & 1 & 1 & & & 2 & 4 \\
\hline 26 & 1 & & & 1 & 3 & 5 \\
\hline 27 & & 2 & & & 8 & 10 \\
\hline 28 & & 9 & & & 4 & 13 \\
\hline
\end{tabular}


450

Vicente Gozálvez Pérez

\begin{tabular}{|l|r|r|r|r|r|r|}
\hline 29 & 5 & 3 & 1 & 1 & 3 & 13 \\
\hline 1930 & 4 & 3 & & 1 & 3 & 11 \\
\hline 31 & 3 & 1 & & 3 & 1 & 8 \\
\hline 33 & 2 & 5 & & 2 & 1 & 10 \\
\hline 34 & 1 & & & & 3 & 4 \\
\hline 35 & 1 & 1 & & & & 2 \\
\hline 36 & 1 & 10 & & 2 & 4 & 17 \\
\hline 37 & 4 & 4 & & & 2 & 11 \\
\hline 38 & 1 & 2 & & & 2 & 5 \\
\hline 39 & 3 & 2 & 2 & 3 & 1 & 11 \\
\hline 1940 & & 1 & & & 7 & 8 \\
\hline 41 & & 6 & & & 5 & 11 \\
\hline 42 & 3 & 4 & & 2 & 2 & 11 \\
\hline Desconocida & 2 & 6 & & & 9 & 18 \\
\hline Total & 19 & 1 & & 3 & 35 & 58 \\
\hline
\end{tabular}

Fuente: AGA, Caja AF-M-2354 


\section{Cuadro VI}

Año 1943. Lugar de procedencia de los colonos españoles asentados en el protectorado de España en Marruecos

\begin{tabular}{|l|r|r|l|}
\hline Lugar de procedencia & \multicolumn{1}{|c|}{ Quert } & \multicolumn{1}{|c|}{ Rif } & Chauén \\
\hline Alicante & $3(1)$ & & \\
\hline Almería & $13(3)$ & 1 & \\
\hline Badajoz & 1 & & \\
\hline Cádiz & 1 & 1 & \\
\hline Granada & 7 & 1 & \\
\hline León & 1 & & \\
\hline Jaén & 3 & 2 & \\
\hline Málaga & 5 & & \\
\hline Murcia & $11(5)$ & & \\
\hline Valencia & 1 & & \\
\hline Vizcaya & 1 & & \\
\hline Melilla & 4 & & \\
\hline Orán & 11 & & \\
\hline Filipinas & 1 & & \\
\hline Tánger & 1 & & \\
\hline
\end{tabular}

Fuente: AGA, AF-M-2354

Nota: Las cifras entre paréntesis, indican los colonos que habiendo nacido en Almería, Murcia o Alicante, emigraron primero al Oranesado, y desde esta colonia francesa pasaron a establecerse en el Protectorado español. 

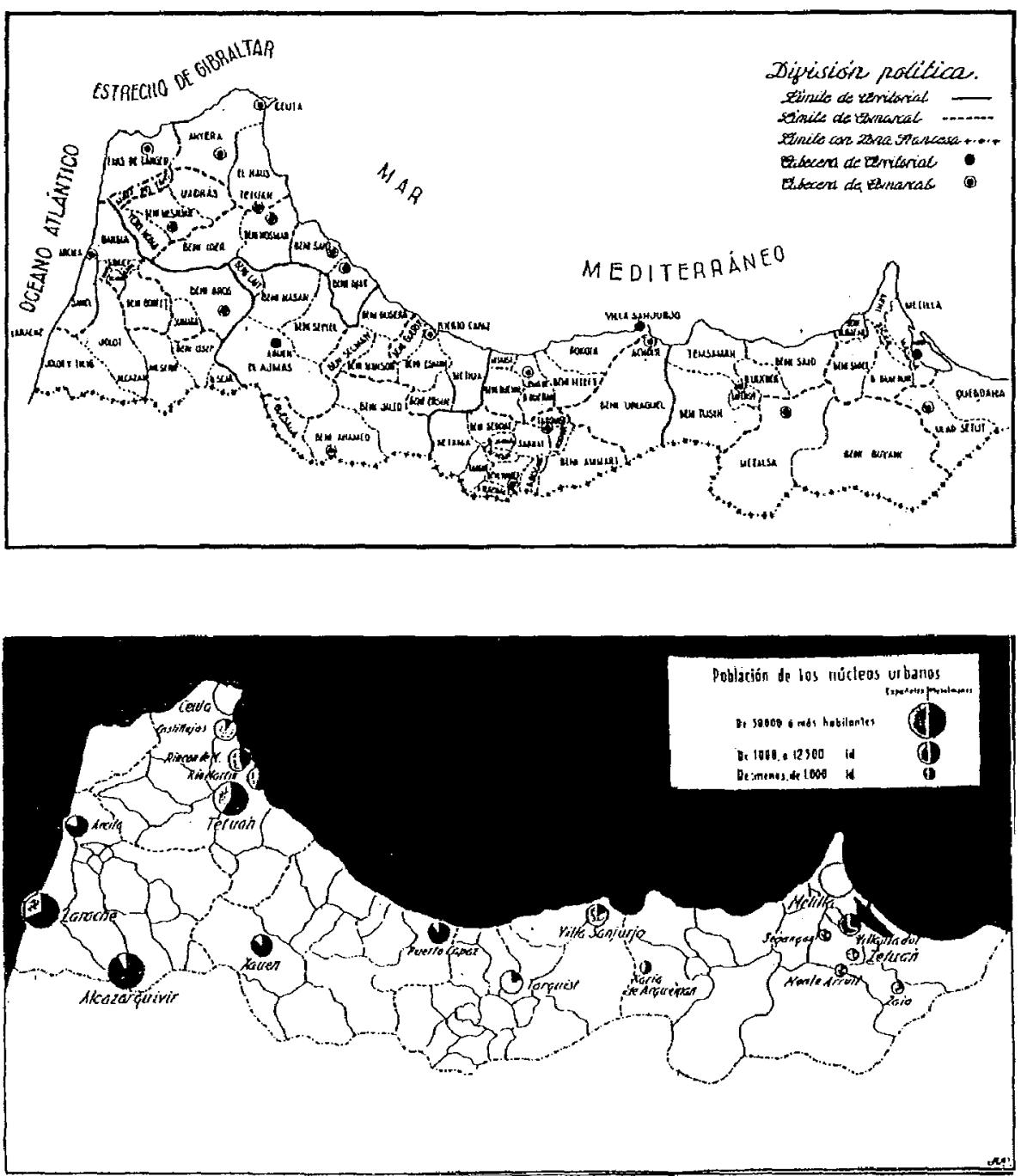

Fig. 1. Protectorado de España en Marruecos. División administrativa y distribución de la población en los núcleos urbanos, según Dirección de Estadística, Ministerio de Trabajo, Zona de Protectorado y de los Territorios de Soberania de España en el norte de Africa. Anuario Estadístico, años 1944 y 1942, respectivamente. 